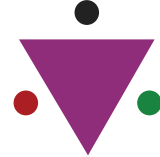

IJCRR Section: Healthcare Sci. Journal Impact Factor: $6.1(2018)$ ICV: 90.90 (2018)

\title{
The Preparedness of India to Fight with COVID 19
}

\author{
Dr. Shilpa Pise
}

Executive Editor, International Journal of Current Research and Review

Email: dua.shilpa@gmail.com

The first case of Covid-19 was reported on Nov 17, 2019 in China and it kept on spreading thereafter in Wuhan but no other country could realize the adverse impact of this deadly virus as Wuhan hide several cases of Covid-19 from world. But when the number of cases kept on growing not only in Wuhan but in many other countries, the adversity of Covid-19 was realized. Wuhan became completely isolated from world to prepare itself ready to fight with deadly virus. Wuhan has built a hospital of 10,000 bed capacity in just 10 days with 100 big machineries and 7,000 workers working day and night.

It is not impossible but difficult to work in same manner in India as Wuhan did in earlier few months. Though many policies have been implemented like travel ban on both international and national level. India has learnt lesson from Italy where number of cases grew so fast that situation became out of control. So many steps have been taken by Indian government to curb the impact of virus. Many states have been locked down to avoid its spread. Maharashtra has reported the highest cases of virus spread. It is difficult to report the exact number of cases as different government data provide varying reports. Depending upon population size, the growth rate of Covid-19is relatively low but severity can increase if all preventive measures will not be implemented.

Here few preventive measures have been enlisted:

1. Locking down state borders can discourage the spread

2. Evacuation of citizens from foreign countries with the help of special flights. This evacuation does not involve only for Indian citizens but also for neighboring friendly citizens.

3. Large and unauthorized gathering has been discouraged

4. Circulation of fake health messages is being avoided and stringent action will be taken for not following the guidelines

5. Work from home policy has been implemented for many government and private organizations

6. Facilitation of diagnosis and detection of virus in various private hospitals is being authorized

No doubt economy will be in downfall because of this pandemic but if situation come under control in shortest possible duration, this will be a win over bad evil and all the nations globally together can overcome the recession. 